\section{Full of Eastern promise}

\section{John Barrow}

Journal of Astrophysics and Astronomy. General editor S. Ramaseshan. 4/yr. (Indian Academy of Sciences.) Rs 36 (personal); Rs 75 (institutional). Chinese Astronomy and Astrophysics. Chief translation editor T. Kiang. $4 / \mathrm{yr}$. (Pergamon.) £100, \$114.28.

I SUPPOSE there are two ways to justify the appearance of a new journal, one geographical, one intellectual. Either you cater for existing disciplines in an area of the world with few indigenous publishing sites or you respond internationally to the emergence of a new discipline or coalition of disciplines. The Indian Journal of Astrophysics and Astronomy (JAA) and Chinese Astronomy and Astrophysics (CAA) are both reflections of the first provocation.

Each issue of JAA contains about eight research articles with no editorials, or book reviews. The number of non-Indian

\section{CHINESE}

ASTRONOMY

\section{AND ASTROPHYSICS}

(Formerly Chinese Astronomy)

contributors is as yet small and the standard of published papers sound if unspectacular. The printing quality is high but the paper poor and liable to discolour with age. The average time between submission and publication of articles is quite short, about three or four months on average. The success of the journal may well depend on whether foreigners or expatriate Indians submit good articles to it. I suspect they will not. At present this journal is a luxury for science libraries but it is extremely inexpensive and for that reason worth serious consideration.

CAA (formerly Chinese Astronomy) is a translation journal covering two Chineselanguage journals, Acta Astronomica Sinica and Acta Astrophysica Sinica. It reflects the rapidly changing nature of Chinese society where perhaps, as in other totalitarian states, no one of intelligence would risk the attempt to do real history, philosophy, sociology or psychiatry, and so the physical and mathematical sciences are of high quality.

The latest issues of the journal reflect keen interest in new ideas in cosmology massive neutrinos, phase transitions and elementary particles. The 1981 issues include a very interesting overview and bibliography of all the modern Chinese articles in astrophysics. The most impressive articles appearing regularly in the journal are those on the history of astronomy - any scholars with interests in the history of astronomy will find remarkable and otherwise inaccessible archival material published here. All astronomy and history of science libraries should consider subscribing, especially since the subscription is moderate and over eighty articles appear in an annual volume.

There are just two unfortunate aspects of the journal, consequences of lax editing and proof-reading. First, the article by Ruffini and Gao in Vol. 5, No.1, is a word for word copy of an article by the same authors published earlier in Physics Letters $B$. If the editors and authors consistently ignore copyright they may have problems. Second, the number of misprints among personal names is so high that the uninformed will have unfortunate experiences with the references (also, annoyingly, Soviet references remain in cyrillic). This aspect of the translation needs to be dramatically improved.

Meanwhile, the references in recent issues double as an entertaining parlour game, "Who's Who in Astrophysics". See if you can identify all the following wellknown physicists and astronomers: Carron, McCleland, Lyubimro, Norikov, Sovel, Saudage (or Sandge), Bawm, Schraman, Radir, Neugebanar, Ress, Morgon, Goldeich, Isreal, Laing, Alven, Berbidge, Saslow, King-Hell, Schener, Clmemnce and Bodenemer.

John Barrow is a Lecturer at the Astronomy Centre, University of Sussex.

\section{Physics from Chinese fields}

\section{George L. Trigg}

Chinese Physics. Managing editor A.W.K. Metzner. 4/yr. (American Institute of Physics.) \$370 US, \$377 elsewhere.

MANY of us now active in physics and astronomy in the Western world grew up, as it were, with no thought that significant work in our field might be going on in China. If we did consider the possibility, we probably assumed that whatever research there was would be duly reported in the "standard" journals - Physical Review, Proceedings of the Physical Society, Zeitschrift für Physik or others of that category. Up until relatively few years ago, we would not have been far wrong.

Within roughly the past decade, the picture has changed. Western observers returning from visits to China consistently report significant amounts of physics research, of respectable quality, being done there. Moreover, especially given the political atmosphere that has existed in China since the fall of the Kuomintang, it is only natural that the Chinese should have inaugurated their own journals. Thus there has grown up a body of literature that is almost completely inaccessible to Western scientists.

Chinese Physics represents an effort to remedy the situation. Its purpose is "to make the best current Chinese research in physics and astronomy accessible in a

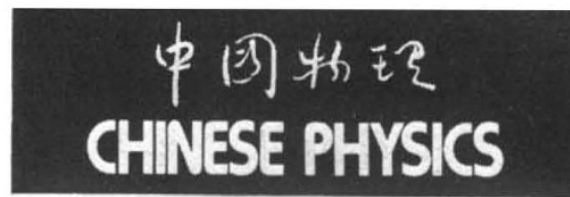

timely and economical fashion to scientists everywhere who do not read Chinese", by the publication of English translations of selected articles from Chinese journals. The selection is in the hands of an editorial board, each member of which scans one or more of the journals covered (originally nine, extended to thirteen as of Vol.2, No.3). The plan is that eventually the selection will take place in manuscript stage, with Chinese and English publication nearly simultaneous. Until that scheme can be fully implemented, the journal has devoted itself to coverage - still selective - of back issues of the Chinese journals.

I am not in a position to judge the quality of the articles presented. I know the reputations of several members of the editorial board, however, and on that basis I am reasonably confident that it will be comparable to that of "standard" journals. The subject coverage of course reflects the emphasis of Chinese physics and astronomy, which is roughly what one might guess: a modest amount of atomic, molecular and nuclear physics, some theoretical astronomy and astrophysics, some particle theory, some plasma work, and a great deal of condensed-matter physics and optics, with considerable emphasis on application.

There are some deficiencies on the production side of the journal, most of which will be noticed only by the trained eye. One, however, is serious: the reproduction of halftone illustrations is generally poor, sometimes to the point of indecipherability. Another noticeable point is that the page dimensions, at least with the margin allowance used, are fully satisfactory for neither one- nor two-column format. Finally, there are still some traces, occasionally strong, of orientalism in the language, which could be eliminated by a stronger editorial hand.

At the current subscription price, the goal of providing economical access to Chinese research is far from realization, at least on an individual basis. Any serious research institution, however, should have the journal on hand.

George L. Trigg is editor of Physical Review Letters for The American Physical Society, Ridge, New York. 